\title{
Photo-Fenton oxidation of phenol with magnetite as iron source
}

\author{
Marco Minella, ${ }^{1}$ Giulia Marchetti, ${ }^{1}$ Elisa De Laurentiis, ${ }^{1}$ Mery Malandrino, ${ }^{1}$ Valter \\ Maurino, ${ }^{1}$ Claudio Minero, ${ }^{1}$ Davide Vione, ${ }^{1, *}$ Khalil Hanna ${ }^{2,3, *}$ \\ ${ }^{1}$ Dipartimento di Chimica, Università di Torino, Via Pietro Giuria 5, 10125 Torino, Italy. \\ ${ }^{2}$ Ecole Nationale Supérieure de Chimie de Rennes, CNRS, UMR 6226, 11 Allée de Beaulieu, CS \\ 50837, 35708 Rennes Cedex 7, France. \\ ${ }^{3}$ Université Européenne de Bretagne, France.
}

* Address correspondence to either author. Tel: +39-011-6705296 (D. Vione), +33-(0)2-23238027 (K. Hanna). E-mail: davide.vione@unito.it (D. Vione), khalil.hanna@ensc-rennes.fr (K. Hanna)

\begin{abstract}
In this work, magnetite-catalyzed Fenton reaction was investigated under UVA irradiation for the degradation of phenol as model compound. Four kinds of magnetite were used having different particle size, surface area and $\mathrm{Fe}^{\mathrm{II}}$ content. Different kinetic behaviors were observed, thereby underscoring the strong implications of surface and chemical properties of magnetite. The size and surface area of the particles seemed to be less important, while the $\mathrm{Fe}^{\mathrm{II}} / \mathrm{Fe}^{\mathrm{III}}$ ratio played some role. Despite the link between magnetite reactivity and its structural $\mathrm{Fe}^{\mathrm{II}}$ content, light-induced reduction of $\mathrm{Fe}^{\mathrm{III}}$ to $\mathrm{Fe}^{\mathrm{II}}$ was found necessary to promote the Fenton-based reactions. As surface $\mathrm{Fe}^{\mathrm{II}}$ may be oxidised or otherwise unavailable, initial photoactivation may be needed to trigger the Fenton reactivity. Two major driving forces were highlighted that account for the photoactivity of magnetite at $\mathrm{pH}$ 3: (i) the formation of intermediates such as hydroquinone that are able to reduce $\mathrm{Fe}^{\mathrm{III}}$ to $\mathrm{Fe}^{\mathrm{II}}$, and (ii) the accumulation of dissolved $\mathrm{Fe}$ due to magnetite dissolution, both in dark and under irradiation. Very interestingly, the photo-Fenton degradation of phenol was also observed under neutral conditions. In this case, for two out of four samples, the degradation rates were quite near those found at $\mathrm{pH} \mathrm{3,} \mathrm{which} \mathrm{is} \mathrm{usually} \mathrm{reported} \mathrm{as} \mathrm{the} \mathrm{optimum} \mathrm{pH}$ value of the process. The magnetite ability to promote photo-Fenton reactions even under circumneutral $\mathrm{pH}$ conditions, the limited iron leaching and its easy magnetic separation makes magnetite a promising catalyst in wastewater treatment applications.
\end{abstract}

Keywords: photo-Fenton; magnetite; advanced oxidations process; heterogeneous photo-Fenton oxidation. 


\section{Introduction}

The classic Fenton process involves aqueous ferrous ions and $\mathrm{H}_{2} \mathrm{O}_{2}$ that react together to form ${ }^{\bullet} \mathrm{OH}$, in a reaction that can be expressed as follows (in acidic solution, $\mathrm{Fe}^{\mathrm{II}}$ is usually present as $\mathrm{Fe}^{2+}$ and $\mathrm{Fe}^{\mathrm{III}}$ may be present as $\left.\mathrm{FeOH}^{2+}\right)[1]$ :

$$
\mathrm{Fe}^{\mathrm{II}}+\mathrm{H}_{2} \mathrm{O}_{2} \rightarrow \mathrm{Fe}^{\mathrm{III}}+\mathrm{OH}^{-}+{ }^{\bullet} \mathrm{OH}
$$

Reaction (1) is a stoichiometric process, but Fe is often used in catalytic amount because of the subsequent pathways of $\mathrm{H}_{2} \mathrm{O}_{2}$ decomposition [2], which regenerate $\mathrm{Fe}^{\mathrm{II}}$ that reacts again in (1). The classical Haber-Weiss view of the process reads as follows [3]:

$$
\begin{aligned}
& \mathrm{FeOH}^{2+}+\mathrm{H}_{2} \mathrm{O}_{2} \rightarrow \mathrm{Fe}^{\mathrm{II}}+\mathrm{HO}_{2}^{\bullet}+\mathrm{H}_{2} \mathrm{O} \\
& \mathrm{FeOH}^{2+}+\mathrm{HO}_{2} \rightarrow \mathrm{Fe}^{\mathrm{II}}+\mathrm{O}_{2}+\mathrm{H}_{2} \mathrm{O}
\end{aligned}
$$

The production of ${ }^{\bullet} \mathrm{OH}$, a powerful reactant that is able to degrade a wide variety of xenobiotics at diffusion-limited reaction rates, accounts for the widespread use of the Fenton reaction among Advanced Oxidation Processes (AOPs) for the abatement of recalcitrant compounds in water and wastewater. Reaction (1) is the fast step of the Fenton process, while reactions $(2,3)$ are considerably slower. Therefore, when $\mathrm{Fe}^{\mathrm{II}}$ and $\mathrm{H}_{2} \mathrm{O}_{2}$ are mixed in the presence of a pollutant, one often observes a very fast first step followed by a considerable slowing down of the reaction. This issue complicates the use of $\mathrm{Fe}^{\mathrm{III}}$, which is much cheaper than $\mathrm{Fe}^{\mathrm{II}}$ in the classic Fenton process. It also explains why several variants of the Fenton reaction have been proposed. An example is the photo-Fenton process, where the formation of $\mathrm{Fe}^{\mathrm{II}}$ from $\mathrm{Fe}^{\mathrm{III}}$ takes place photochemically (L in reaction (5) is an organic ligand such as oxalate) $[4,5]$ :

$$
\begin{aligned}
& \mathrm{FeOH}^{2+}+\mathrm{h} v \rightarrow \mathrm{Fe}^{\mathrm{II}}+{ }^{\bullet} \mathrm{OH} \\
& \mathrm{Fe}^{\mathrm{III}}-\mathrm{L}+\mathrm{h} v \rightarrow \mathrm{Fe}^{\mathrm{II}}+\mathrm{L}^{+\bullet}
\end{aligned}
$$

The Fenton reaction is usually carried out in acidic conditions (optimum $\mathrm{pH}$ is 3), not only to keep $\mathrm{Fe}^{\mathrm{III}}$ dissolved but mostly because the ${ }^{\bullet} \mathrm{OH}$ generation in reaction (1) has maximum effectiveness in an acidic environment. Furthermore, among the $\mathrm{Fe}^{\mathrm{III}}$ species, the $\mathrm{FeOH}^{2+}$ hydroxocomplex that prevails at $\mathrm{pH} 3$ has the highest reactivity towards reduction by $\mathrm{H}_{2} \mathrm{O}_{2}$ and $\mathrm{HO}_{2}{ }^{\bullet}$ in reactions $(2,3)[2$, $3,6]$. The $\mathrm{pH}$ effect is a major issue where the still unresolved complexity of the Fenton mechanism comes to the surface, behind the apparent straightforwardness of reactions (1-5). Indeed, reaction (1) actually involves the formation of a highly oxidized Fe adduct, often indicated as ferryl (e.g. ferryl ion $\mathrm{FeO}^{2+}$ ), which does not necessarily evolve into ${ }^{\bullet} \mathrm{OH}[1,7,8]$. The ${ }^{\bullet} \mathrm{OH}$ formation is most effective (but by no means quantitative) at $\mathrm{pH} 3$ and it usually decreases at higher or lower $\mathrm{pH}$ 
values $[2,3]$. Therefore, it is not surprising to find differences between the Fenton process and the expected reactivity of ${ }^{\bullet} \mathrm{OH}[1,7,9]$.

Recently, magnetite ( $\mathrm{Fe}^{\mathrm{II}} \mathrm{Fe}_{2}{ }^{\mathrm{III}} \mathrm{O}_{4}, \mathrm{Fe}^{\mathrm{II}}-\mathrm{Fe}^{\mathrm{III}}$ mixed valence oxide) was successfully used as iron source in heterogeneous Fenton reactions, because $\mathrm{Fe}^{\mathrm{II}}$ plays an important role in the initiation of the Fenton process according to the classical Haber-Weiss mechanism. Magnetite, pristine, doped or coupled with other oxides $\left(\right.$ e.g. $\left.\mathrm{CeO}_{2}\right)$ was shown to effectively catalyze the oxidative degradation of target compounds at circumneutral $\mathrm{pH}$. It also exhibited good structural stability and excellent reusability [10-19]. Magnetite can be synthesized in the laboratory by various biotic and abiotic pathways. Abiotic procedures to form magnetite include co-precipitation of soluble $\mathrm{Fe}^{\mathrm{II}}$ and $\mathrm{Fe}^{\mathrm{III}}$ species, oxidation of hydroxylated $\mathrm{Fe}^{\mathrm{II}}$ species and ferric oxides transformation [20-24]. The morphology, crystallography and specific surface area of natural or synthetic magnetite can vary widely $[25,26]$. Similarly to other iron oxides, magnetite exists as micrometric and nanometric particles in many natural and engineered environments. Because the specific surface area of nanosized particles is very large, their surface reactivity is exalted and they can play a potentially pre-eminent role in sorption and/or redox processes.

The heterogeneous photo-Fenton reaction can solve the problem of eliminating and re-using Fe from the reaction system at the end of the process, but the separation of the solid phase is still an open issue. The separation problem is even more important in the case of oxide nanoparticles, which are potentially more reactive because of the favorable surface-to-volume ratio. From this point of view, the fact that magnetite undergoes very easy magnetic separation from aqueous systems makes it a very interesting material to be tested for photo-Fenton reactivity. Moreover, it is very interesting to check whether, as for dark reactivity, the photo-activity of magnetite is maintained under circumneutral $\mathrm{pH}$ conditions, which would overcome the need of $\mathrm{pH}$ adjustment. At circumneutral $\mathrm{pH}$ the operational mechanism of the photo-Fenton process is still controversial, in particular in the presence of organic ligands for iron (EDTA, humic acids...) [27, 28]. Quite surprisingly, very few data are available about the use of magnetite in photo-Fenton chemistry. To fill in this knowledge gap, the present work has the goal of studying the photo-Fenton reactivity of magnetite toward the degradation of phenol. The latter was chosen because it is a substrate of well known behavior and it can be very helpful in the elucidation of reaction pathways [29].

The photo-Fenton reactivity of magnetite could depend on characteristics and surface properties such as crystallinity, surface area, $\mathrm{Fe}^{\mathrm{II}}$ content or $\mathrm{Fe}^{\mathrm{II}} / \mathrm{Fe}^{\mathrm{III}}$ structural ratio. For this reason, dark and irradiation experiments were carried out with four different kinds of magnetite (two synthetic and two commercial) having different morphologies and structural properties. The aim was to point out the effects of particle size, surface area and Fe speciation on the magnetite ability to promote heterogeneous Fenton or photo-Fenton reactions, a topic that has attracted very little attention in the literature to date. Phenol was chosen as model compound in this study because of its well-known 
photo-Fenton degradation, which considerably aids in the understanding of the reaction pathways $[30,31]$.

\section{Experimental}

\subsection{Reagents and materials.}

Phenol (purity grade 99\%), \%), 1,10-phenanthroline (99\%), hydroquinone (98\%), $\mathrm{H}_{3} \mathrm{PO}_{4}(85 \%)$, $\mathrm{HClO}_{4}(70 \%)$, magnetite (97\%) and methanol (gradient grade) were purchased from Aldrich, magnetite (98\%) from Prolabo, $\mathrm{H}_{2} \mathrm{O}_{2}(35 \%)$ from VWR International. All reagents were used as received, without further purification. The aqueous solutions were prepared by using water of MilliQ purity (TOC $<2 \mathrm{ppb}$, resistivity $\geq 18.2 \mathrm{~m} \Omega \mathrm{cm}$ ).

\subsection{Synthesis of magnetite samples}

Experiments were conducted with four different kinds of magnetite. Among them, two (S1 and S2) were prepared in the lab from two different Fe(III)-oxyhydroxides, the third one (S3) was purchased from Prolabo and the fourth (S4) from Aldrich. S1 and S2 were prepared by starting from 2-line ferrihydrite and lepidocrocite $(\gamma-\mathrm{FeOOH})$, respectively. The ferrihydrite and lepidocrocite were synthesized as explained in previous work [32], according to the methods proposed by Schwertmann and Cornell [33]. All the $\mathrm{Fe}^{\mathrm{III}}$ precipitates were washed several times to remove electrolytes, centrifuged and then dried. Starting from these materials, S1 and S2 were then prepared by $\mathrm{Fe}^{\mathrm{II}}$-induced mineralogical transformations of synthetic ferric oxyhydroxides, as explained in detail in previous works $[32,34,35]$. The suspensions were vigorously stirred for two days, they were then centrifuged and the solid was dried in a glove box.

\subsection{Sample characterization}

To identify the crystal structure of minerals, the solid samples were analyzed by X-ray powder diffraction (XRD). The XRD data were collected with a D8 Bruker diffractometer, equipped with a monochromator and a position-sensitive detector. The X-ray source was a Co anode $(\lambda=0.17902$ $\mathrm{nm})$. The diffractogram was recorded in the $3-64^{\circ} 2 \theta$ range, with a $0.0359^{\circ}$ step size and a collection time of $3 \mathrm{~s}$ per point.

Transmission Electron Microscopy (TEM) analysis was also performed to obtain information regarding morphology, size, shape and arrangement of particles. TEM observations were carried out with a Philips CS20 TEM (200 kV) coupled with an EDAX energy dispersive X-ray spectrometer. The solid powder was re-suspended in $2 \mathrm{~mL}$ ethanol under ultrasonication and a drop of the 
suspension was evaporated on a carbon-coated copper grid, which was placed on filter paper for analysis.

The specific surface area of the iron oxides was determined by multipoint $\mathrm{N}_{2}-\mathrm{BET}$ analysis, using a Coulter (SA 3100) surface area analyzer. The point of zero charge (PZC) of the tested magnetites was determined by potentiometric titration of the oxides in a thermostatic double-walled Pyrex cell at $293 \mathrm{~K}$ in $0.001,0.01$ and $0.1 \mathrm{M} \mathrm{NaCl}$ solutions, according to the method of Parks and de Dyne [36]. The $\mathrm{N}_{2}$ gas was constantly passed through the suspensions to bubble out $\mathrm{CO}_{2}$. The $\mathrm{pH}$ value of the suspensions was adjusted with titrant solutions $(\mathrm{HCl}$ or $\mathrm{NaOH})$ and recorded with an Orion $\mathrm{pH}$ meter model 710A, connected to a combined glass electrode. Blank titrations were also performed with similar solutions in the absence of solid.

The $\mathrm{Fe}^{\mathrm{II}}$ content in the oxide structure was determined by chemical analysis after acid dissolution with $6 \mathrm{M} \mathrm{HCl}$. Ferrous and total iron concentrations were determined using a modified 1,10phenanthroline method [37]. The $\mathrm{Fe}^{\mathrm{II}} / \mathrm{Fe}^{\mathrm{III}}$ ratios of oxides are reported in Table 1. All chemical analyses were performed in triplicate.

The degree of aggregation of the magnetite primary particles in circumneutral and acidic $\left(10^{-3} \mathrm{M}\right.$ $\mathrm{HClO}_{4}$ ) aqueous suspensions was assessed with an ALV-NIBS (Langen, Germany) Dynamic Light Scattering (DLS) instrument, equipped with a Ne-He laser and an ALV-5000 multiple tau digital correlator. The scattered light intensity for each sample was recorded for at least $30 \mathrm{~s}$ at $298 \mathrm{~K}$, at an angle of $173^{\circ}$ with respect to the incident beam. For each sample the measurement was repeated for at least three times on 30,20 and $10 \mathrm{mg} \mathrm{dm}^{-3}$ suspensions. The hydrodynamic radius was calculated using the cumulant method and it was expressed as the average value for all the tested concentrations.

\subsection{Irradiation experiments.}

Magnetite stock suspensions at $1 \mathrm{~g} \mathrm{~L}^{-1}$ loading were prepared by ultrasonication (Branson 2200 ultrasonic bath, $40 \mathrm{kHz}$ ). The suspensions for irradiation ( $50 \mathrm{~mL}$ total volume in a beaker) were prepared by adding magnetite for a final loading of $0.2 \mathrm{~g} \mathrm{~L}^{-1}$ (unless otherwise reported), as well as $\mathrm{H}_{2} \mathrm{O}_{2}$ (where relevant) and phenol from separate stock solutions. The natural $\mathrm{pH}$ value of the system was $\sim 6$, measured with a combined glass electrode connected to a Metrohm $713 \mathrm{pH}$ meter. When required, the $\mathrm{pH}$ of the system was adjusted to 3 upon addition of $\mathrm{HClO}_{4}$. Irradiation took place under a Philips TL 09N UVA lamp, with emission maximum at $365 \mathrm{~nm}$. The lamp irradiance on top of the irradiated suspensions was $18 \mathrm{~W} \mathrm{~m}^{-2}$ in the $295-400 \mathrm{~nm}$ range, measured with a CO.FO.ME.GRA. (Milan, Italy) power meter. The TL 09N lamp was chosen because UVA radiation is present in the sunlight spectrum, while preliminary experiments showed that visible light alone was ineffective in inducing degradation processes. Samples were mechanically stirred 
during irradiation. A picture showing the adopted experimental set-up is provided in the Supplementary Material (hereafter SM), in Figure SM1.

At selected time intervals, $1 \mathrm{~mL}$ aliquots (precisely measured) were withdrawn from the irradiated suspension, added with $0.5 \mathrm{~mL}$ methanol to quench the Fenton reaction, and filtered on Millipore HV syringe filters (Teflon, $0.45 \mu \mathrm{m}$ pore diameter). The clear solutions underwent analysis by highperformance liquid chromatography coupled to diode array detection (HPLC-DAD). The instrument used was a VWR Hitachi Elite chromatograph, equipped with L-2200 Autosampler (injection volume $60 \mu \mathrm{L}$ ), L-2130 quaternary pump for low-pressure gradients, L-2300 column oven (set at $40^{\circ} \mathrm{C}$ ), and L-2455 DAD detector. The column used was a RP-C18 LichroCART (VWR Int., length $125 \mathrm{~mm}$, diameter $4 \mathrm{~mm}$ ), packed with LiChrospher $100 \mathrm{RP}-18$ (5 $\mu \mathrm{m}$ diameter). Elution was carried out with a 40:60 mixture of methanol: aqueous $\mathrm{H}_{3} \mathrm{PO}_{4}(\mathrm{pH} 2.8)$ at $1.0 \mathrm{~mL} \mathrm{~min}^{-1}$ flow rate, with detection at $220 \mathrm{~nm}$. Under these conditions the retention times were $1.5 \mathrm{~min}$ for hydroquinone (HQ) and $4.9 \mathrm{~min}$ for phenol. The column dead time was $0.9 \mathrm{~min}$.

In some runs the concentration of dissolved Fe was also checked. In this case $5 \mathrm{~mL}$ aliquots were withdrawn, magnetite was separated by a magnet and the supernatant was filtered. If needed, $50 \mu \mathrm{L}$ of concentrated $\mathrm{HClO}_{4}$ were added to acidify the solution. The clear sample was analyzed with a Varian Liberty 100 Inductively Coupled Plasma-Optical Emission Spectrometer (ICP-OES), provided with a Czerny-Turner monochromator, a Sturman-Masters spray chamber, a V-groove nebulizer and a radio frequency (RF) generator at $40.68 \mathrm{MHz}$.

\section{Results and Discussion}

\subsection{Synthesis and characterization of the magnetite samples}

Magnetite $\left(\mathrm{Fe}_{3} \mathrm{O}_{4}\right)$ is the only pure oxide of mixed valence and it is usually represented by the formula $\left(\mathrm{Fe}^{\mathrm{III}}\right)_{\mathrm{tet}}\left[\mathrm{Fe}^{\mathrm{III}} \mathrm{Fe}^{\mathrm{II}}\right]_{\mathrm{oct}} \mathrm{O}_{4}[20]$. It has a cubic spinel structure with iron in both tetrahedral and octahedral sites. Tested magnetites were characterized by XRD (Fig. 1a). For the S3 and S4 samples, five diffraction peaks at $2 \theta=21.2^{\circ}, 35^{\circ}, 41.2^{\circ}, 50.4^{\circ}$ and $62.8^{\circ}$ could be assigned to $\mathrm{Fe}_{3} \mathrm{O}_{4}$, magnetite [33]. The d-space values of these main peaks were 2.53, 2.96, 2.09, 4.85 and 1.71 $\AA$, which may respectively correspond to the more intense lines of magnetite $311,220,400,111$ and 422. It should be noted that the XRD pattern of S1 and S2 shows the same peaks that are less intense. The broad nature and low intensity of the peaks in the spectra of S1 or S2 can result from nanosized particles (Fig.1b), which may exhibit poor crystallinity [33, 38].

TEM images show that magnetite particles are highly aggregated and exhibit irregular shapes and non-uniform size (Fig. 1b). S1 particles were smaller with quasi-spherical shape. The shape of S2 
particles was between hexagonal to octahedral, while S3 exhibited non-uniform size and shape. The TEM image of S4 shows more or less rhombohedral particles, with crystals varying between 100 and $300 \mathrm{~nm}$ in length. TEM combined with energy-dispersive X-ray spectrometry (EDXS) yields an elemental analysis of the sample, so that elemental ratios can be calculated by EDXS and compared with the known mineralogical composition. EDX microanalysis showed the characteristic Fe/O ratio of magnetite $(\sim 0.75)$ for all samples. The particle diameter range deduced from all images is reported in Table 1.

As the $\mathrm{Fe}^{\mathrm{II}}$ content is a key parameter in the heterogeneous Fenton reaction, the $\mathrm{Fe}^{\mathrm{II}} / \mathrm{Fe}^{\mathrm{III}}$ ratio was determined by chemical analysis for each magnetite sample and it is reported in Table 1. S1 and S4 have the lowest $\mathrm{Fe}^{\mathrm{II}}$ content and they are quite far from stoichiometric magnetite [24]. While S4 is a commercial sample, S1 may still contain some impurities as residuals of ferrihydrite particles from the synthesis method. TEM images of S1 and its high surface area and PZC value (close to that of ferrihydrite, i.e. $~ 8.2$ [13]) support this statement. Overall, the tested magnetites have different particle size $(\mathrm{S} 1<\mathrm{S} 2<\mathrm{S} 4<\mathrm{S} 3)$, while the reverse order was found for BET surface area and PZC (Table 1). The $\mathrm{pH}$ values of the point of zero charge $\left(\mathrm{pH}_{\mathrm{PZC}}\right)$ estimated from potentiometric titration are close to those reported in the literature (Table 1) [39, and references therein].

Figure 1c shows the hydrodynamic radii of the tested magnetites, both at circumneutral $\mathrm{pH}$ and at pH $3\left(1 \mathrm{mM} \mathrm{HClO}_{4}\right)$. Inspection of the particle size data reported in Table 1 (solid phase) and in Figure 1c (aqueous suspensions) suggests the following statements: (i) magnetite particles show a high degree of aggregation in aqueous suspension; (ii) the dimensions of the aggregates follow the same order as the primary particles $(\mathrm{S} 1<\mathrm{S} 2<\mathrm{S} 4<\mathrm{S} 3$ ); (iii) aggregate size is slightly lower in acidic media, probably due to electrostatic repulsion between the positively charged particles at $\mathrm{pH}$ $\leq \mathrm{pH}_{\mathrm{PZC}}$.

\subsection{Photo-Fenton degradation of phenol}

Preliminary experiments showed that the photo-Fenton system with magnetite had an optimal loading of $0.2 \mathrm{~g} \mathrm{~L}^{-1}$ (higher loadings did not increase the rate of degradation considerably, see Figure SM2 in $\mathrm{SM}$ ), and that $1 \mathrm{mM} \mathrm{H}_{2} \mathrm{O}_{2}$ was quite effective in inducing degradation of $0.1 \mathrm{mM}$ phenol. Therefore, such conditions were chosen as the test ones to compare the behavior of the different magnetite samples.

Figure 2 reports the time trend of phenol in the photo-Fenton system with the different magnetite samples at $\mathrm{pH} 3$. Blank runs were also carried out, where one or more components of the system $\left(\mathrm{H}_{2} \mathrm{O}_{2}\right.$, magnetite and irradiation) were removed to highlight their effect toward phenol degradation. As far as blank runs are concerned, the following observations can be made: (i) phenol did not undergo significant photolysis under UVA at the adopted time scale $(4 \mathrm{~h})$, and also its degradation 
in the presence of $\mathrm{H}_{2} \mathrm{O}_{2}$ under irradiation (which could produce ${ }^{\circ} \mathrm{OH}$ [9]) was negligible; (ii) magnetite did not induce significant phenol degradation when irradiated without $\mathrm{H}_{2} \mathrm{O}_{2}$ (suggesting that no photocatalytic processes were operational with irradiated magnetite) or when added with $\mathrm{H}_{2} \mathrm{O}_{2}$ in the dark. The blank runs also showed that phenol adsorption on magnetite is negligible, which suggests that removal (when applicable) was due to actual transformation and not just to phase transfer. The results of most blank runs are not reported in Figure 2 for readability issues. Irradiation of magnetite with $\mathrm{H}_{2} \mathrm{O}_{2}$ was required to trigger reactivity. The presence of $\mathrm{Fe}^{\mathrm{II}}$ at the magnetite surface might suggest the possibility of a dark Fenton reaction, but Figure 2 shows that for a 4-h time scale (and in the absence of hydroquinone, vide infra) no significant phenol degradation was observed in the dark, in the presence of magnetite ( $\mathrm{S} 1$ to S4) and $\mathrm{H}_{2} \mathrm{O}_{2}$.

As far as the photo-Fenton experiments are concerned (magnetite $+\mathrm{H}_{2} \mathrm{O}_{2}$ under irradiation), Figure 2 shows that complete or almost complete phenol degradation could be achieved within $4 \mathrm{~h}$ or less. $\mathrm{S} 2$ and S3 were the most photoreactive samples, with less than $2 \mathrm{~h}$ irradiation required to halve the concentration of phenol. In the case of S1 and S4, 2-3 h irradiation was required to obtain the same result. The size of particles and particle aggregates did not seem to play a key role in reactivity, because S1 had the smallest particles and the particles of S4 were smaller compared to S3, but S2 and S3 were more reactive compared to S1 and S4. Interestingly, the most reactive samples (S2 and S3) were also those showing the highest structural $\mathrm{Fe}^{\mathrm{II}}$ content (see Table 1). This observation may be consistent with a previous report on the magnetite-catalyzed Fenton reaction in the dark [15]. However, it is unlikely that the higher reactivity of S2 and S3 under photo-Fenton conditions may be explained by a simple mechanism in which $\mathrm{Fe}^{\mathrm{II}}$ is directly released in solution where it takes part to the Fenton reaction. Indeed, if it were the case, one should expect significant phenol transformation with magnetite $+\mathrm{H}_{2} \mathrm{O}_{2}$ in the dark, which was on the contrary negligible at the time scale of our experiments. The facts that light was needed to induce phenol transformation and that the role of irradiation was not linked to the photolysis of $\mathrm{H}_{2} \mathrm{O}_{2}$ (no transformation took place with $\mathrm{H}_{2} \mathrm{O}_{2}$ alone) might suggest that $\mathrm{Fe}^{\mathrm{III}}$ photoreduction to $\mathrm{Fe}^{\mathrm{II}}$ (see e.g. reaction 4 or its corresponding process on the oxide surface) was required to trigger the degradation process.

The most remarkable feature of phenol transformation with irradiated magnetite $+\mathrm{H}_{2} \mathrm{O}_{2}$ is represented by the shape of its time evolution. In all the cases, although with different kinetics, phenol transformation was initially slow and then it gradually accelerated, before slowing down when almost all the substrate was degraded. Similar profiles have been observed in the phototransformation of nitrobenzene in the presence of soluble $\mathrm{Fe}^{\mathrm{III}}$ and $\mathrm{H}_{2} \mathrm{O}_{2}$ [40]. In AOPs, this behavior is less common than first-order degradation kinetics [29] and it deserves explanation. A first possibility (phenol adsorption on magnetite) can be excluded by blank experiments. An alternative explanation is that time is required for Fe dissolution to take place, and that the phenol reaction rate is highly dependent on the concentration of dissolved Fe. ICP-OES measurements indicated that total $\mathrm{Fe}$ was gradually released in solution from magnetites at $\mathrm{pH} 3$ in the presence of 
phenol and $\mathrm{H}_{2} \mathrm{O}_{2}$, both in the dark and under irradiation (see Fig. 3). The gradual increase of dissolved Fe concentration is consistent with the observed time trend of phenol, because phenol transformation rate is low when dissolved $\mathrm{Fe}$ is also low and it increases with increasing $\mathrm{Fe}$ in solution. However, a closer look at the experimental data indicates that the concentration of dissolved $\mathrm{Fe}$ is not the only or the main factor involved. The highest values of $\mathrm{Fe}$ concentration in solution were observed in the presence of magnetite $\mathrm{S} 3$ and $\mathrm{H}_{2} \mathrm{O}_{2}$ in the dark, which induced negligible transformation of phenol. In the irradiated systems, similar Fe time trends were observed with $\mathrm{S} 1, \mathrm{~S} 3$ and $\mathrm{S} 4$, despite differences in reactivity. An important issue is that $\mathrm{Fe}^{\mathrm{II}}$ is considerably more reactive than $\mathrm{Fe}^{\mathrm{III}}$ towards $\mathrm{H}_{2} \mathrm{O}_{2}$, thus the speciation of $\mathrm{Fe}$ in the studied systems plays an even more important role than its total concentration in solution. Unfortunately it was not possible to quantify dissolved $\mathrm{Fe}^{\mathrm{II}}$ in the studied systems, because the colorimetric method for $\mathrm{Fe}^{\mathrm{II}}$ is less sensitive than the ICP-OES technique for total $\mathrm{Fe}$, and because fast reaction with $\mathrm{H}_{2} \mathrm{O}_{2}[2,3]$ would keep the $\mathrm{Fe}^{\mathrm{II}}$ concentration low.

In the dark Fenton reaction it has been shown that some aromatic compounds such as catechol and hydroquinone or even humic acids can enhance substrate degradation [40-42]. An important issue is that these compounds are involved in the reduction of $\mathrm{Fe}^{\mathrm{III}}$ to $\mathrm{Fe}^{\mathrm{II}}$, which considerably accelerates the slow second step of the Fenton process. In such a case, the shape of phenol time evolution would be due to the fact that the intermediates need first to be formed from phenol before they can accelerate the reaction. The pathway of $\mathrm{Fe}^{\mathrm{III}}$ reduction by hydroquinone (HQ) is shown below [41]:

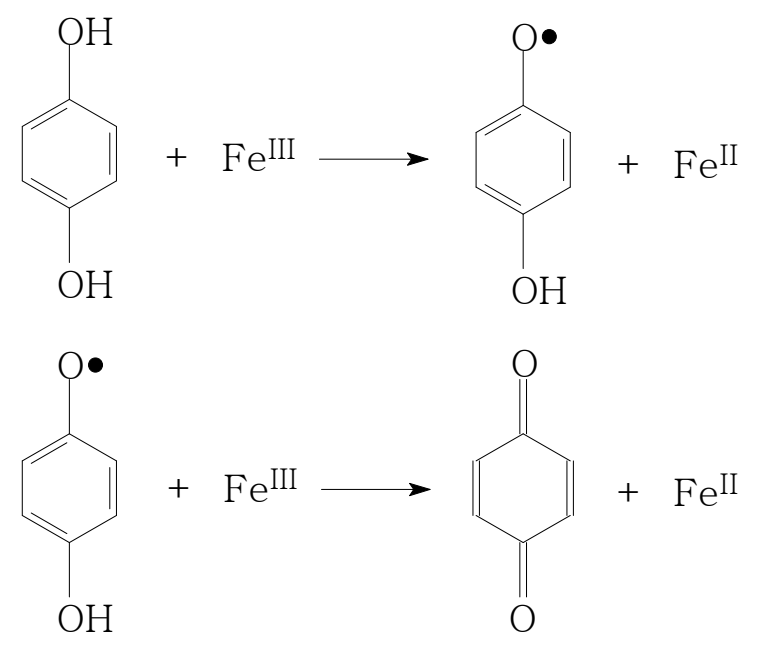

Catechol and HQ are formed in the Fenton degradation of phenol [40], as typical intermediates of the reaction between phenol itself and ${ }^{\circ} \mathrm{OH}$ or related/mimicking oxidants. In our system HQ could for instance be detected at concentration values up to $4-5 \mu \mathrm{M}$, as a result of the formationtransformation budget. To see if HQ can be responsible for the observed kinetics of phenol transformation, it was added to the system from the very start at an initial concentration of $50 \mu \mathrm{M}$. If the hypothesis depicted in reaction (6) is correct, the availability of HQ in much higher concentration should considerably enhance phenol transformation. Figure 2 shows that the presence 
of HQ considerably accelerated phenol degradation, the most remarkable acceleration being observed with S1 and S4. This happens despite the fact that HQ is a scavenger of reactive species (including ${ }^{\circ} \mathrm{OH}$ [43]), thus it could compete with phenol for photo-Fenton transformation. Such a finding provides evidence that the reduction of $\mathrm{Fe}^{\mathrm{III}}$ to $\mathrm{Fe}^{\mathrm{II}}$ is very important in the photo-Fenton transformation of phenol in the presence of magnetite.

In the case of $\mathrm{S} 2$ (or $\mathrm{S} 3$ ) $+\mathrm{H}_{2} \mathrm{O}_{2}$, addition of $\mathrm{HQ}$ induced phenol degradation even in the dark (Figure 2), while no dark transformation could be observed without HQ. In contrast, HQ did not induce dark transformation of phenol in the presence of $\mathrm{H}_{2} \mathrm{O}_{2}$ with $\mathrm{S} 1$ and $\mathrm{S} 4$. This finding suggests that $\mathrm{Fe}^{\mathrm{III}}$ reduction would be easier for $\mathrm{S} 2$ and $\mathrm{S} 3$ compared to $\mathrm{S} 1$ and $\mathrm{S} 4$. At equal $\mathrm{pH}$ conditions, the speciation (and, therefore, the reactivity) of dissolved $\mathrm{Fe}^{\mathrm{III}}$ would be the same with all the studied magnetite samples. Therefore, differences in reactivity should involve $\mathrm{Fe}^{\mathrm{III}}$ at the surface of the solid. At first sight, S2 and S3 differ from S1 and S4 because of the higher content of structural $\mathrm{Fe}^{\mathrm{II}}$. This is not easily or directly linked to the photo-Fenton reactivity, because Fe ${ }^{\mathrm{III}}$ reduction is needed to start the reaction. However, a different stoichiometry of the solids could modify the reactivity or the accessibility of the surface sites, including the $\mathrm{Fe}^{\mathrm{III}}$ ones.

Figure 4 reports the time evolution of phenol (initial concentration $0.1 \mathrm{mM}$ ) in the photo-Fenton reaction ( $1 \mathrm{mM} \mathrm{H}_{2} \mathrm{O}_{2}+0.2 \mathrm{~g} \mathrm{~L}^{-1}$ magnetite under UVA) at $\mathrm{pH}$, the latter not varying significantly during irradiation. Blank runs are also reported, where no phenol degradation was observed. Differently from $\mathrm{pH} 3, \mathrm{pH} 6$ is definitely not the optimum for the Fenton or photo-Fenton reaction to take place [44-48]. This issue might account for the lack of reactivity at $\mathrm{pH} 6$ of the magnetite samples $\mathrm{S} 1$ and $\mathrm{S} 4$, which were also the least reactive at $\mathrm{pH} 3$. In the case of S2 and most notably $\mathrm{S} 3$, phenol transformation at $\mathrm{pH} 6$ was not much modified compared to $\mathrm{pH} 3$, when considering either the shape of the curve or the time required to reach a certain degree of phenol transformation. These data confirm the high reactivity of S2 and S3 under all the studied conditions. The time evolution of dissolved $\mathrm{Fe}$ at $\mathrm{pH} 6$ is reported in Figure 3, where it is compared with the corresponding data at $\mathrm{pH} 3$. The release of dissolved Fe in the dark was always lower at $\mathrm{pH} 6$ than at $\mathrm{pH} 3$, while under irradiation the difference between the two $\mathrm{pH}$ values was much less important. It is possible that the photoassisted reduction of $\mathrm{Fe}^{\mathrm{III}}$ would facilitate the release of iron in solution and that this process would become particularly important at $\mathrm{pH}$ 6. However, as already observed at $\mathrm{pH} \mathrm{3,} \mathrm{there} \mathrm{was} \mathrm{no} \mathrm{straightforward} \mathrm{correlation} \mathrm{between} \mathrm{dissolved} \mathrm{Fe} \mathrm{concentration} \mathrm{and} \mathrm{the} \mathrm{ability}$ of magnetite S1-S4 to degrade phenol. Furthermore, while the much lower dissolved Fe under irradiation at $\mathrm{pH} 6$ compared to $\mathrm{pH} 3$ could be consistent with the lack of photoreactivity of S4 at $\mathrm{pH} 6$, in the case of $\mathrm{S} 1$ (unreactive at $\mathrm{pH} 6$ as well) the amount of dissolved Fe under irradiation was comparable to (and even higher than) that at $\mathrm{pH} 3$. In the cases of S2 and S3, which showed comparable photoreactivity toward phenol at both $\mathrm{pH}$ values, the Fe concentration was similar at $\mathrm{pH} 3$ and 6 only for low irradiation times. At longer times, Fe accumulated in solution at pH 3 but not at $\mathrm{pH}$ 6. Such an overall scenario could be a consequence of the complexity of the processes 
involved. In the presence of $\mathrm{H}_{2} \mathrm{O}_{2}$, dissolved $\mathrm{Fe}$ would mainly be in the form of $\mathrm{Fe}^{\mathrm{III}}[2,3]$, which could take part to the Fenton reaction only by undergoing reduction to $\mathrm{Fe}^{\mathrm{II}}$. The $\mathrm{pH}$ variation in the 3-6 range could have variable effects on the reduction process: on the one side, the concentration of $\mathrm{FeOH}^{2+}$ (the $\mathrm{Fe}^{\mathrm{III}}$ form that undergoes the easiest reduction) would decrease with increasing $\mathrm{pH}$, but on the other side $\mathrm{HO}_{2}{ }^{\bullet}$ would be deprotonated to $\mathrm{O}_{2}^{-\bullet}$ that is more active towards $\mathrm{Fe}^{\mathrm{III}}$ reduction [2, 3]. Furthermore, reduction could involve $\mathrm{Fe}^{\mathrm{III}}$ on the oxide surface in addition to the dissolved one.

There are very different literature reports concerning the performance of the $\mathrm{Fe}^{\mathrm{III}}$-based heterogeneous photo-Fenton processes at $\sim$ neutral $v s$. acidic $\mathrm{pH}$. While in some cases considerable reactivity under neutral conditions is reported [49-51], in other cases a substantial decrease of the performance has been observed with increasing $\mathrm{pH}[52,53]$. It is possible that, as hypothesized in the present work, the effect of $\mathrm{pH}$ on reactivity depends on several factors such as Fe solubility and speciation and the availability and speciation of reducing agents, with different outcomes depending on the particular system under study.

Interestingly, $50 \mu \mathrm{M}$ HQ at $\mathrm{pH} 6$ slightly enhanced phenol transformation in the case of S2, but inhibited it with S3 (see Figure 4). A possible explanation is that HQ can both reduce $\mathrm{Fe}^{\mathrm{III}}$ to $\mathrm{Fe}^{\mathrm{II}}$, thereby enhancing the Fenton process, and compete with phenol for the reaction with transient species including ${ }^{\circ} \mathrm{OH}$ [43]. The latter phenomenon would inhibit phenol transformation, and the HQ effect would be a balance between opposite trends. HQ could thus favor or inhibit phenol degradation depending on the magnetite sample and the operational conditions. There is also evidence that ${ }^{\circ} \mathrm{OH}$ and/or another oxidant with similar reactivity was involved in the transformation of phenol in the studied systems. Indeed, the addition of 2-propanol (0.01 M initial concentration) as ${ }^{\bullet} \mathrm{OH}$ scavenger [43] to phenol $+\mathrm{H}_{2} \mathrm{O}_{2}+$ magnetite ( $\mathrm{S} 2$ or S3) under irradiation at both pH 3 and 6 was able to quench phenol degradation.

\section{Conclusions}

In this work, effective phenol degradation was obtained upon irradiation of magnetite in the presence of $\mathrm{H}_{2} \mathrm{O}_{2}$ (heterogeneous photo-Fenton conditions). The initially low reaction rate considerably increased as the reaction progressed, most likely because of: (i) the formation of intermediates such as $\mathrm{HQ}$ that are able to reduce $\mathrm{Fe}^{\mathrm{III}}$ to $\mathrm{Fe}^{\mathrm{II}}$, which takes part to the Fenton reaction, and (ii) the presence of dissolved Fe due to magnetite dissolution, both in dark and under irradiation. The need of $\mathrm{Fe}^{\mathrm{III}}$ reduction, which is also supported by the important role of irradiation, might look surprising when considering that magnetite contains structural $\mathrm{Fe}^{\mathrm{II}}$. It is thus possible that the latter is not readily available for the Fenton reaction and that some form of initial activation (e.g. partial iron photodissolution) is needed. On the other hand, phenol degradation was most effectively achieved by the samples having the highest content of structural $\mathrm{Fe}^{\mathrm{II}}$. The size of the 
primary particles seems to be less important, because it was not correlated with photo-Fenton activity in the studied samples. However, the size effect could be largely offset by important aggregation phenomena in the aqueous suspensions.

From an applicative point of view, the most interesting features of magnetite as shown in this study are:

- Reactivity upon absorption of UVA radiation, which makes cheap sunlight potentially applicable to carry out the reaction.

- Ability of some samples (most notably S2 and S3) to maintain reactivity also under circumneutral $\mathrm{pH}$ conditions, which could save the need to adjust and back-adjust $\mathrm{pH}$.

- Limited iron leaching (up to or below the ppm range), which keeps dissolved Fe safely below the limits for wastewater discharge.

- Magnetic behavior, which greatly helps in the separation of magnetite from treated wastewater.

\section{Acknowledgements}

The $\mathrm{PhD}$ grant of EDL was financially supported by Progetto Lagrange - Fondazione CRT (Torino, Italy). GM also acknowledges financial support from Progetto Lagrange - Fondazione CRT (borse di ricerca applicata). 


\section{References}

[1] J.J. Pignatello, D. Liu, P. Huston, Environ. Sci. Technol. 33 (1999) 1832-1839.

[2] J. De Laat, H. Gallard, Environ. Sci. Technol. 33 (1999) 2726-2732.

[3] H. Gallard, J. De Laat, B. Legube, New J. Chem. 22 (1998) 263-268.

[4] O. Legrini, E. Oliveros, A.M. Braun, Chem. Rev. 93 (1993) 671-698.

[5] E. Guivarch, S. Trevin, C. Lahitte, M.A. Oturan, Environ. Chem. Lett. 1 (2003) 38-44.

[6] S.W. Lam, K. Chiang, T.M. Limb, R. Amal, G.K.C. Low, J. Catal. 234 (2005) 292-299.

[7] S.H. Bossmann, E. Oliveros, S. Göb, S. Siegwart, E.P. Dahlen, Jr L. Payawan, M. Straub, M. Wörner, A.M. Braun, J. Phys. Chem. A 102 (1998) 5542-5550.

[8] C. Minero, M. Lucchiari, V. Maurino, D. Vione, RSC Adv. 3 (2013) 26443-26450.

[9] R. Zellner, M. Exner, H. Herrmann, J. Atmos. Chem. 10 (1990) 411-425.

[10] K. Hanna, T. Kone, G. Medhagi, Catal. Commun. 9 (2008) 955-959.

[11] R. Matta, K. Hanna, S. Chiron, Sci. Tot. Environ. 385 (2007) 242-251.

[12] R. Matta , K. Hanna, S. Chiron, Sep. Purif. Technol. 61 (2008) 442-446.

[13] R. Matta, K. Hanna, T. Kone, S. Chiron, Chem. Eng. J. 144 (2008) 453-458

[14] X. Xue, K. Hanna, M. Abdelmoula, N. Deng, Appl. Catal. B-Environ. 89 (2009) 432-440.

[15] X. Xue, K. Hanna, N. Deng, J. Hazard. Mater. 166 (2009) 407-414.

[16] X. Xue, K. Hanna, C. Despas, F. Wu, N. Deng, J. Mol. Catal. A-Chem 311 (2009) 29-35.

[17] L. Xu, J. Wang, Environ. Sci. Technol. 46 (2012) 10145-10153.

[18] X. Liang, Y. Zhong, S. Zhu, L. Ma, P. Yuan, J. Zhu, H. He, Z. Jiang. J. Hazard. Mater. 199200 (2012) 247-254.

[19] Y. Zhong, X. Liang, Y. Zhong, J. Zhu, S. Zhu, P. Yuan, H. He, J. Zhang. Water Res. 4 (2012) 4633-4644.

[20] R.M. Cornell, U. Schwertmann, The iron oxides: Structures, Properties, Reactions, Occurrences and Uses, Wiley-VCH Verlag GmbH \& Co., Weinheim, 2003.

[21] S. Laurent, D. Forge, M. Port, A. Roch, C. Robic, L. Vander Elst, R. N. Muller, Chem. Rev. 108 (2008) 2064-2110.

[22] R.L. Valentine, H.C.A. Wang, J. Environ. Eng. 124 (1998) 31-38.

[23] C.M. Miller, R.L. Valentine, Water Res. 33 (1999) 2805-2816.

[24] A. Zegeye, M. Abdelmoula, M. Usman, K. Hanna, C. Ruby, Am. Miner. 96 (2011)1410-1413.

[25] T. Sugimoto, E. Matijević. J. Colloid Interface Sci. 74 (1980) 227-243.

[26] H. Itoh, T. Sugimoto, J. Colloid Interface Sci. 265 (2003) 283-295.

[27] A.W. Vermilyea, B.M. Voelker, Environ. Sci. Technol. 43 (2009) 6927-6933.

[28] J. Gomis, R.F. Verchera, A.M. Amat, D.O. Mártire, M.C. González, A. Bianco Prevot, E. Montoneri, A. Arques, L. Carlos, Catal. Today 209 (2013) 176-180.

[29] E. Pelizzetti, C. Minero, Comments. Inorg. Chem. 15 (1994) 297-337.

[30] R. Gonzalez-Olmos, M.J. Martin, A. Georgi, F.D. Kopinke, I. Oller, S. Malato, Appl. Catal. B: Environ. 125 (2012) 51-58.

[31] C.P. Huang, Y.H. Huang, Appl. Catal. A: Gen. 357 (2009) 135-141.

[32] M. Usman, M. Abdelmoula, K. Hanna, B. Grégoire, P. Faure, C. Ruby, J. Solid State Chem. 194 (2012) 328-335.

[33] U. Schwertmann, R.M. Cornell, Iron oxides in the laboratory: preparation and characterization, Wiley- VCH, New York, 2000.

[34] M. Usman, M. Abdelmoula, P. Faure, C. Ruby, K. Hanna, Geoderma 197-198 (2013) 9-16.

[35] M. Usman, K. Hanna, M. Abdelmoula, A. Zegeye, P. Faure, C. Ruby, Appl. Clay Sci. 64 (2012) 38-43.

[36] G.A. Parks, P.L. J. Bruyn, Phys. Chem. 66 (1962) 967-973.

[37] H. Tamura, K. Goto, T. Yotsuyanagi, M. Nagayama, Talanta 21 (1974) 314-318. 
[38] S.H. Xuan, L.Y. Hao, W.Q. Jiang, X.L. Gong, Y. Hu, Z.Y. Chen, J. Magn. Mater. 308 (2007) 210-213.

[39] T.J. Daou, S. Begin-Colin, J.M. Greneche, F. Thomas, A. Derory, P. Bernhardt, P. Legare, G. Pourroy, Chem. Mater. 19 (2007) 4494-4505.

[40] L. Carlos, D. Fabbri, A.L. Capparelli, A. Bianco Prevot, E. Pramauro, F. G. Einschlaga, J. Photochem. Photobiol. A-Chem. 201 (2009) 32-38.

[41] F. Chen, W. Ma, J. He, J. Zhao, J. Phys. Chem. A 106 (2002) 9485-9490.

[42] D. Vione, F. Merlo, V. Maurino, C. Minero, Environ. Chem. Lett. 2 (2004) 129-133.

[43] G.V. Buxton, C.L. Greenstock, W.P. Helman, A.B. Ross, J. Phys. Chem. Ref. Data 17 (1988) 513-886.

[44] I. Arslan, I.A. Balcioglu, D.W. Bahnemann, Dyes Pigments 47 (2000) 207-218.

[45] B. Zhao, G. Mele, I. Pio, J. Li, L. Palmisano, G. Vasapollo, J. Hazard. Mater. 176 (2010) 569574.

[46] O. Abida, M. Kolar, J. Jirkovsky, G. Mailhot, Photochem. Photobiol. Sci. 11 (2012) 794-802.

[47] Y.L. Wu, H.X. Yuan, G.R. Wei, S.D. Zhang, H.J. Li, W.B. Dong, Environ. Sci. Pollut. Res. 20 (2013) 3-9.

[48] L. Prieto-Rodriguez, D. Spasiano, I. Oller, I. Fernandez-Calderero, A. Aguera, S. Malato, Catal. Today 209 (2013) 188-194.

[49] F. Martinez, G. Calleja, J. A. Melero, R. Molina, Appl. Catal. B: Environ. 60 (2005) 181-190.

[50] F. Martinez, G. Calleja, J. A. Melero, R. Molina, Appl. Catal. B: Environ. 70 (2007) 452-460.

[51] L. F. Gonzalez-Bahamon, F. Mazille, L. N. Benitez, C. Pulgarin, J. Photochem. Photobiol. A: Chem. 217 (2011) 201-206.

[52] J. Y. Feng, X. J. Hu, P. L. Yue, Wat. Res. 40 (2006) 641-646.

[53] B. Iurascu, I. Siminiceanu, D. Vione, M. A. Vicente, A. Gil, Wat. Res. 43 (2009) 1313-1322. 
Table 1. Some properties of the magnetite samples used in this study.

\begin{tabular}{|c|c|c|c|c|}
\hline Magnetite samples & $\begin{array}{l}\text { Particle size } \\
\text { range }\end{array}$ & $\begin{array}{c}\text { SSA BET } \\
\left(\mathrm{m}^{2} \mathrm{~g}^{-1}\right)\end{array}$ & PZC & $\begin{array}{c}\mathrm{Fe}^{\mathrm{II}} / \mathrm{Fe}^{\mathrm{III}} \\
\text { ratio }\end{array}$ \\
\hline S1 & $30-50 \mathrm{~nm}$ & $75 \pm 2$ & 8.1 & $0.34 \pm 0.2$ \\
\hline S2 & $60-80 \mathrm{~nm}$ & $26 \pm 1$ & 7.8 & $0.42 \pm 0.2$ \\
\hline S3 & $1-2 \mu \mathrm{m}$ & $1.7 \pm 0.2$ & 7.4 & $0.43 \pm 0.2$ \\
\hline S4 & $100-300 \mathrm{~nm}$ & $8.5 \pm 0.5$ & 7.6 & $0.30 \pm 0.2$ \\
\hline
\end{tabular}


(a)

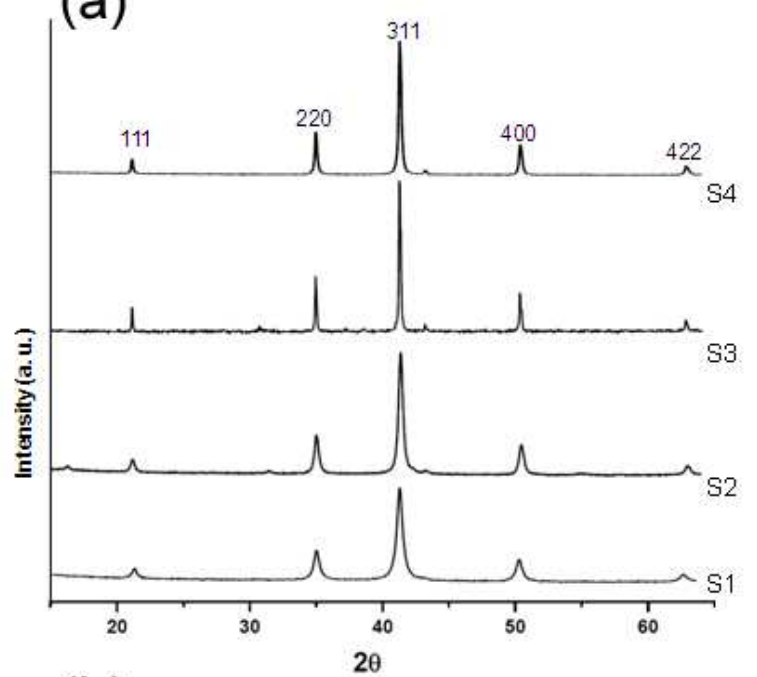

(c)

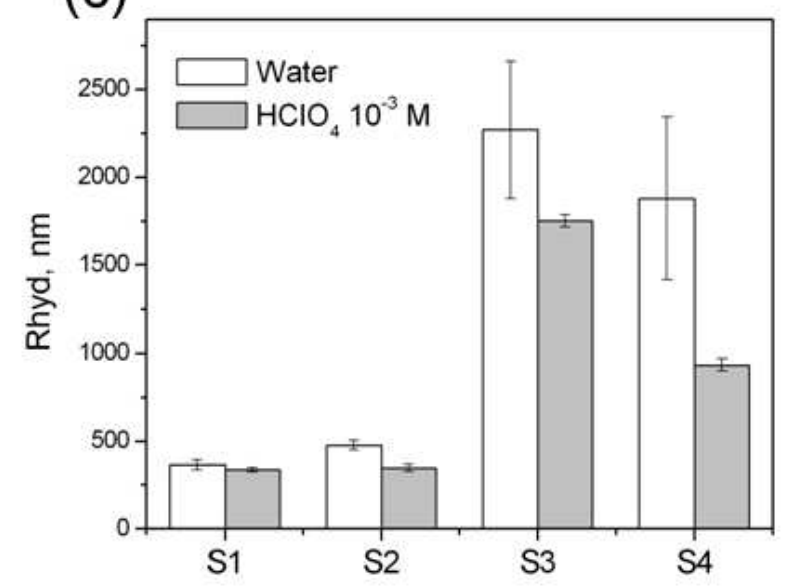

(b)
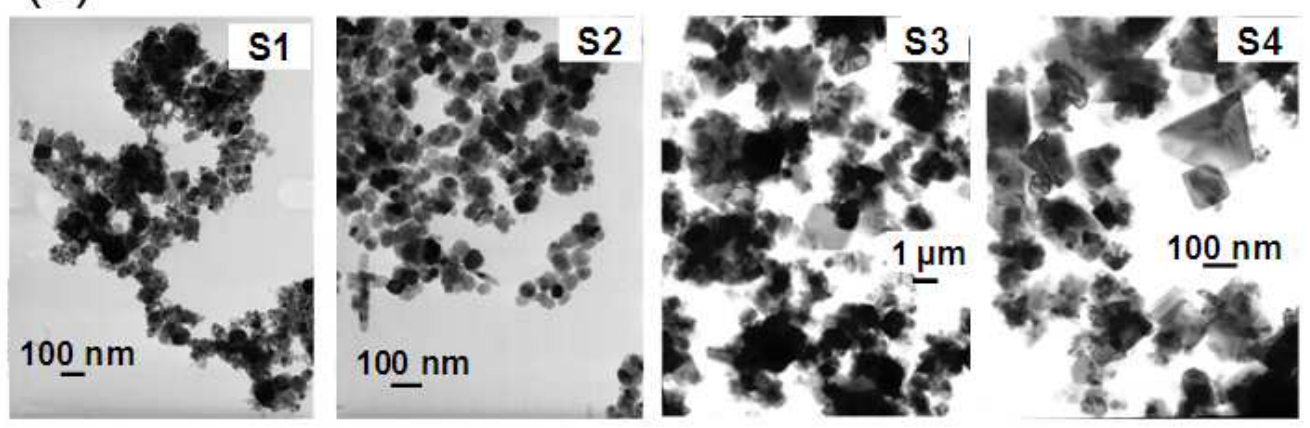

Figure 1: XRD (a) and TEM (b) images of the four used magnetite samples; (c) Hydrodynamic radii $\left(\mathrm{R}_{\text {hyd }}\right)$ of the magnetite particles/aggregates, measured by Dynamic Light Scattering in pure water and in $1 \mathrm{mM} \mathrm{HClO}_{4}$. Error bars represent 95\% confidence intervals. 


\section{S1}

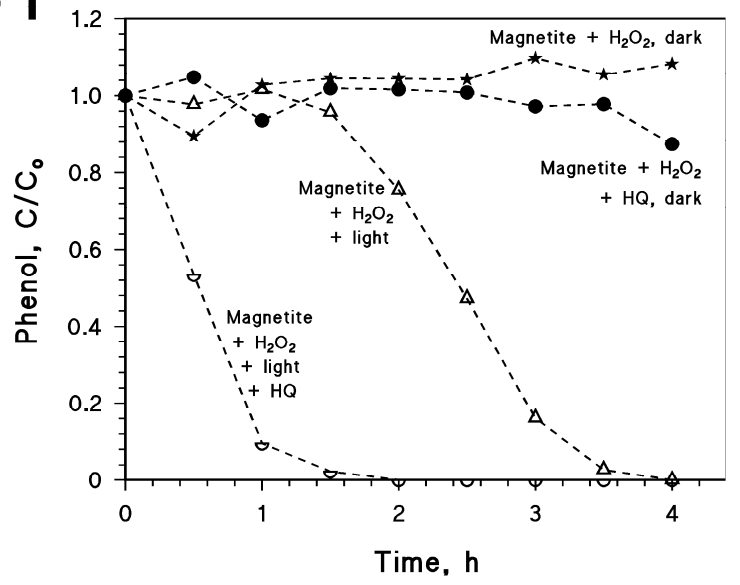

S3

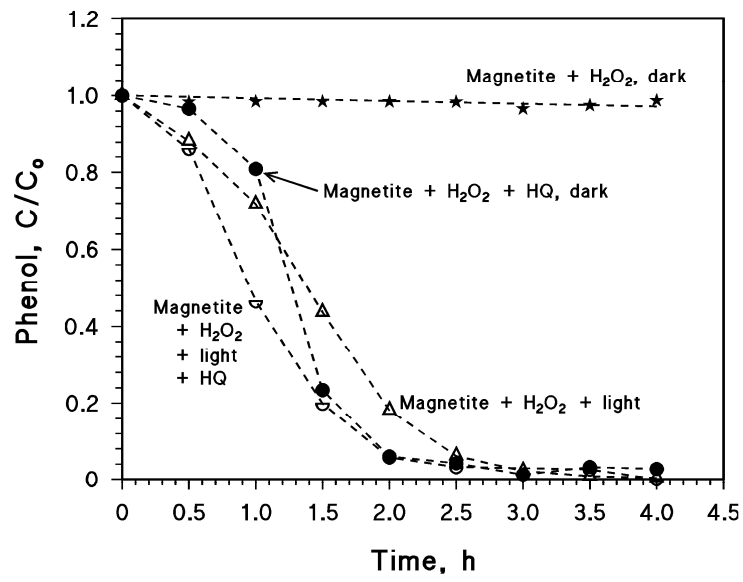

S2

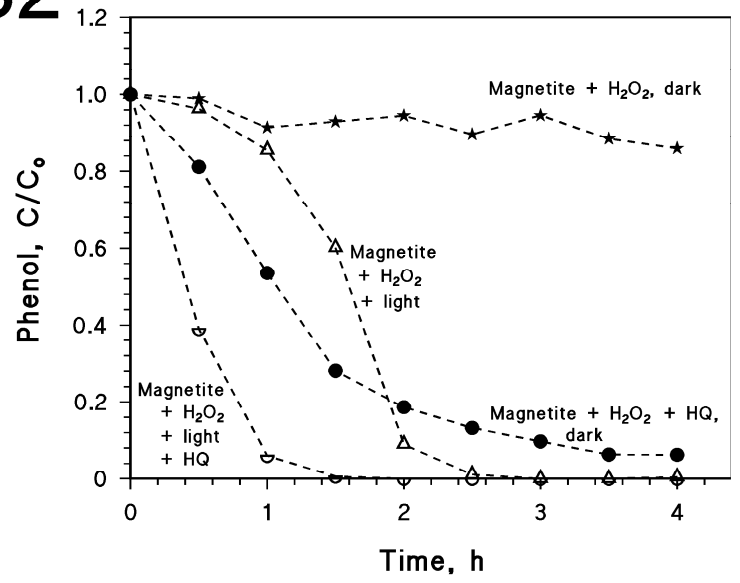

S4

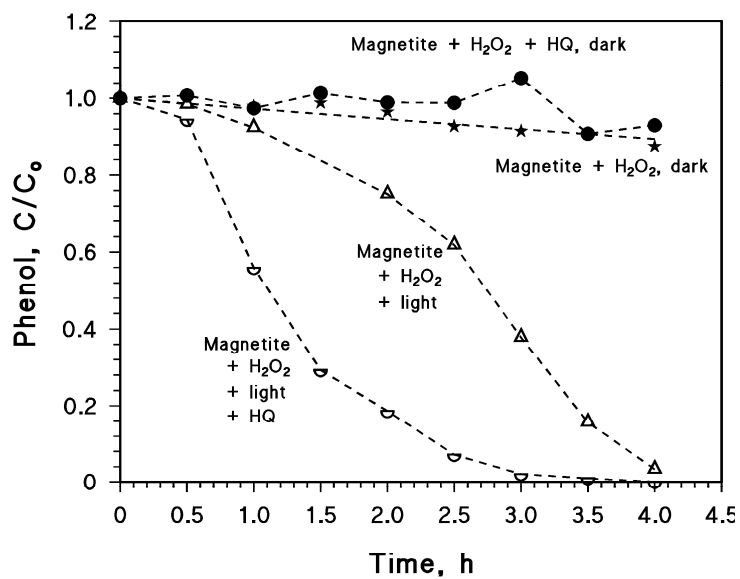

Figure 2. Time trend of phenol (initial concentration $0.1 \mathrm{mM}, \mathrm{pH} 3$ by $\mathrm{HClO}_{4}$ ) under photo-Fenton conditions (phenol $+\mathrm{H}_{2} \mathrm{O}_{2}+$ magnetite $\mathrm{S} 1-\mathrm{S} 4+\mathrm{UVA}$ ) and in blank runs. When relevant, other conditions were as follows: $1 \mathrm{mM} \mathrm{H}_{2} \mathrm{O}_{2}, 0.2 \mathrm{~g} \mathrm{~L}^{-1}$ magnetite loading, 50 $\mu \mathrm{M}$ added $\mathrm{HQ}$. 

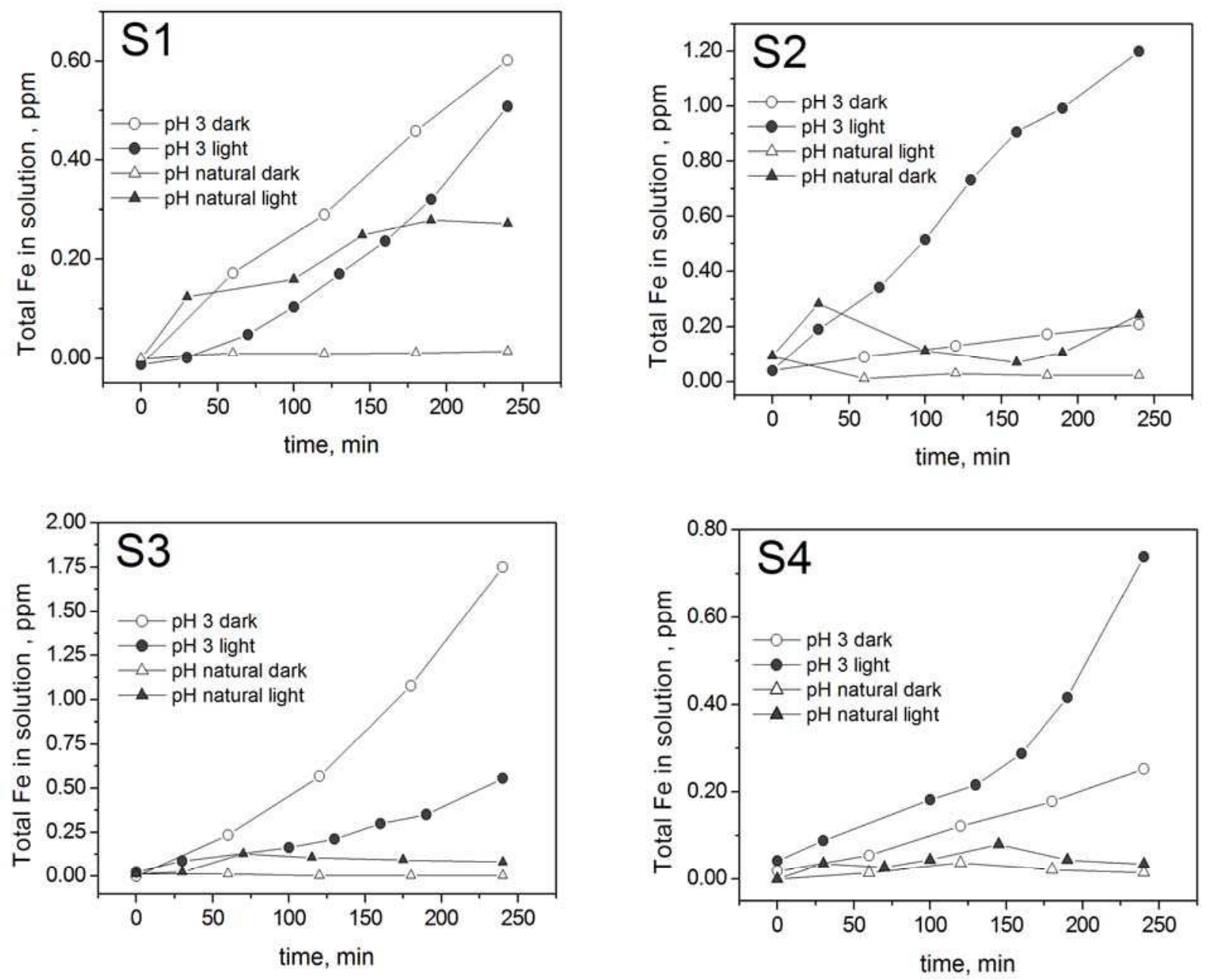

Figure 3. Total iron released in solution, both in the dark (open symbols) and under irradiation (solid symbols), at $\mathrm{pH} 3$ by $\mathrm{HClO}_{4}$ (circles) and at $\mathrm{pH} 6$ (natural $\mathrm{pH}$, triangles), in the presence of the studied magnetite samples. Conditions were as follows: initial phenol concentration $0.1 \mathrm{mM}, 1 \mathrm{mM} \mathrm{H}_{2} \mathrm{O}_{2}, 0.2 \mathrm{~g} \mathrm{~L}^{-1}$ magnetite loading. 

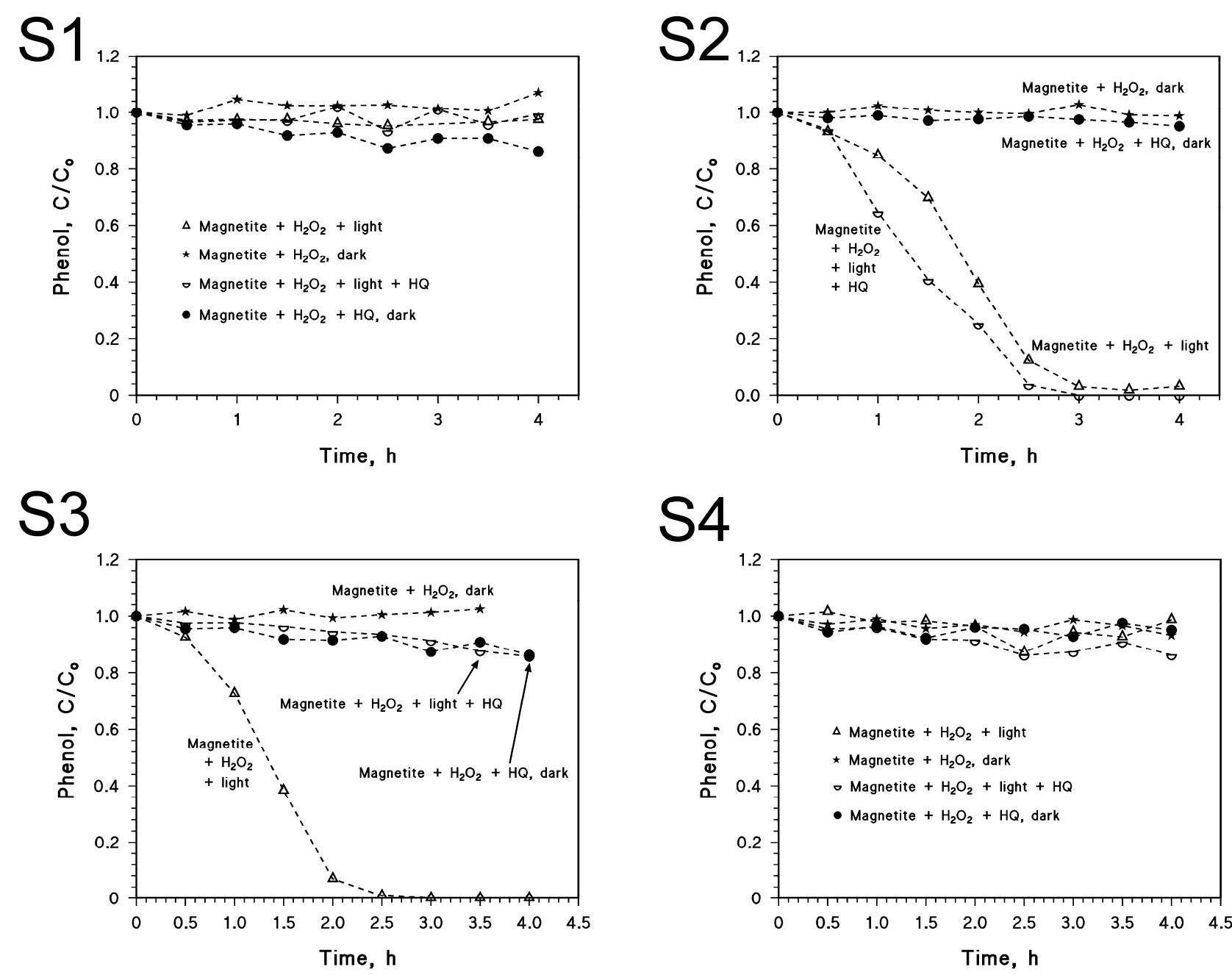

\section{S4}

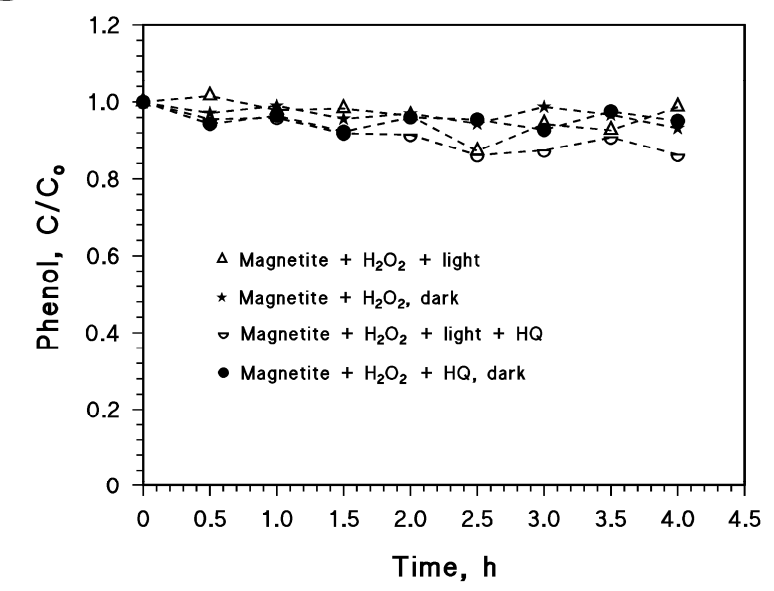

Figure 4. Time trend of phenol (initial concentration $0.1 \mathrm{mM}, \mathrm{pH}$ ) under photo-Fenton conditions (phenol $+\mathrm{H}_{2} \mathrm{O}_{2}+$ magnetite $\mathrm{S} 1-\mathrm{S} 4+\mathrm{UVA}$ ) and in blank runs. When relevant, other conditions were as follows: $1 \mathrm{mM} \mathrm{H}_{2} \mathrm{O}_{2}, 0.2 \mathrm{~g} \mathrm{~L}^{-1}$ magnetite loading, $50 \mu \mathrm{M}$ added HQ. 